\title{
Labor Trafficking Victimization among Farmworkers in North Carolina: Role of Demographic Characteristics and Acculturation ${ }^{1}$
}

Kelle Barrick, Research Criminologist

Center for Justice, Safety, and Resilience

RTI International $^{2}$

Pamela K. Lattimore, Director

Center for Justice, Safety, and Resilience

RTI International

Wayne J. Pitts, Research Criminologist

Center for Justice, Safety, and Resilience

RTI International

3040 Cornwallis Road

Research Triangle Park

North Carolina 27709-2194

Sheldon X. Zhang, Professor

Department of Sociology

San Diego State University

San Diego, California 92182

Corresponding author: Kelle Barrick: 1919 541-6435: kbarrick@ rti.org

\begin{abstract}
Human trafficking is a hidden domestic and international problem of unknown numbers and unsubstantiated estimates. Most research on labor trafficking has focused on known cases through conducting stakeholder interviews and reviewing police and court case files. This limited prior research suggests that demographic characteristics and level of acculturation may impact one's risk for labor trafficking victimization. However, these relationships have not been consistently demonstrated. The current research explores two primary research questions: (1) how prevalent is labor trafficking and other labor exploitation among farmworkers in North Carolina; and (2) do individual-level characteristics or circumstances place a person at greater risk of labor trafficking or other labor exploitation. This was accomplished by conducting 380 inperson interviews with migrant farmworkers in North Carolina. We used three strategies to identify migrant farmworkers: (1) attendance at community events; (2) lists of labor camps known to advocacy organizations; and (3) other public venues farmworkers visit.

Based on descriptive statistics and a logistic regression analysis, we present results on the extent of farmworker abuse and exploitation, and discuss future research in this area.
\end{abstract}

Keywords: Human Trafficking; Labor Exploitation; Migrant Farmworkers; Acculturation 
Labor Trafficking Victimization among Farmworkers in North Carolina: Role of Demographic Characteristics and Acculturation - Barrick, Lattimore, Pitts and Zhang

\section{Introduction}

Human trafficking is a hidden domestic and international problem of unknown numbers and unsubstantiated estimates. The International Labor Organization (ILO) estimated that there are nearly 10 million people forced to work by private agents and enterprises worldwide (Belser, de Cock and Mehran, 2005). Of these, the ILO estimates that while about 1.4 million are in commercial sexual exploitation, the overwhelming majority (7.8 million) are in forced labor situations. Yet, among known trafficking cases approximately $79 \%$ have been sex trafficking (United Nations Office on Drugs and Crime, 2009), which suggests that labor trafficking may be under-identified. If labor trafficking is under-identified, and thus under-investigated and underprosecuted, it is incumbent on researchers to determine why this is the case in order to move the field forward. Unfortunately, labor trafficking has gained little attention relative to sex trafficking, which has remained front and center in the anti-trafficking movement (Goździak and Bump, 2008). Recent research suggests a lack of systematic and reliable data on labor trafficking (Government Accountability Office, 2006; Goździak and Bump, 2008; Laczko, 2003; Laczko and Gramegna, 2003).

Given the hidden nature of labor trafficking and the difficulties in studying hidden populations, it is perhaps not surprising that empirical research is limited. Indeed, most of the existing research on human trafficking has relied on surveys of law enforcement and victim services providers about their experiences with trafficking cases and case reviews (Goździak and Bump, 2008). However, labor trafficking is a hidden crime that only rarely comes to the attention of law enforcement or service providers and, when it does, it may not be recognized as trafficking. When sex trafficking victims are misidentified as prostitutes, a review of law enforcement case files may identify trafficking cases that were processed as prostitution or other related crimes instead of trafficking. Labor trafficking, however, does not have an analogous criminal activity (i.e., work in jobs that may result in exploitation is legal), suggesting that it may be even more difficult to locate cases because there may be no law enforcement file. Also, labor trafficking victims who are in the country illegally may be afraid to reach out for assistance (Clawson, Dutch, Solomon and Grace, 2009), may not know that they are being trafficked (Bales and Lize, 2005; Clawson, Dutch, Lopez and Tiapula, 2008; Garrett, 2008), and they are seldom referred to services by police or medical providers, in contrast to sex trafficking victims (Minnesota Statistical Analysis Center, 2006).Thus, looking for labor trafficking cases solely in law enforcement and court files will likely overlook the majority of labor trafficking incidents. Yet, most research on labor trafficking has focused only on cases known to law enforcement (Clawson, Dutch and Commings, 2006; Clawson et al., 2008; Farrell, McDevitt and Fahy, 2008; Newton, Mulcahy and Martin, 2008), with a recent exception (see Zhang, 2012).

Although the body of prior research on labor trafficking is small and underdeveloped, it has given us some insight into individual characteristics, such as immigration status, sex, age, and isolation (Logan, Walker and Hunt, 2009), that might make someone more vulnerable to 
trafficking. However, this information has been gleaned primarily from those who come in contact with victims and therefore excludes characteristics of hidden victims. Based on previous work and the limitations therein, the current research seeks to identify potential trafficking victims in order to better understand patterns of exploitation so that strategies can be developed to aid in the identification of labor trafficking crimes. To this end, we conducted interviews with 380 migrant farmworkers in North Carolina. Responses from the interviews are used to identify the level and type of abuse and exploitation workers experienced and to examine whether demographic characteristics and level of acculturation are associated with trafficking and other forms of abuse.

\section{Defining Labor Trafficking}

The results from past surveys of state and local law enforcement suggest that definitions of labor trafficking and its components are perceived as vague, with trafficking often being confused with smuggling (Farrell et al, 2008; Laczko, 2002). Indeed, a recent study reported that local human trafficking stakeholders (e.g., law enforcement and service providers) were unable to distinguish trafficking from smuggling (Newton et al., 2008). Moreover, even Immigration and Customs Enforcement, the branch of the Department of Homeland Security responsible for human trafficking investigations, was not correctly distinguishing between smuggling and trafficking as recently as 2004 (U.S. Department of Justice, 2006).

Smuggling consists of "the facilitation, transportation, attempted transportation, or illegal entry of a person(s) across an international border in violation of one or more countries laws, either clandestinely or through deception, such as the use of fraudulent documents," (Human Smuggling and Trafficking Center, 2006, p. 2). The Trafficking Victims Protection Act (TVPA) was passed by the U.S. Congress in 2000 and defines labor trafficking as the recruitment, harboring, transportation, provision, or obtaining of a person for labor or services through the use of force, fraud, or coercion for the purpose of subjection to involuntary servitude, peonage, debt bondage, or slavery. Whereas smuggling often includes two willing parties, the purpose of trafficking is to exploit the victim (Human Smuggling and Trafficking Center, 2006). Before individual indicators of trafficking can be identified, it is essential to understand the difference between smuggling and trafficking.

A proportion of illegal immigration is accomplished with the aid of smugglers who are paid to convey willing immigrants to a desired country-in this case, the United States. Among individuals who enter illegally, either on their own or with help from smugglers, it is suspected that some fall prey to traffickers. For example, smuggling may become trafficking when individuals become so deeply indebted to their transporters that they fall into debt bondage (Chin, 1999). Although the individual may agree to work for the smuggler or his designee until the smuggling fees are paid, the situation becomes trafficking if force, fraud, or coercion is involved. Finally, there are the individuals who are trafficked from the outset; that is, moved or held against their will either transnationally or domestically for labor (or sex). 
Labor Trafficking Victimization among Farmworkers in North Carolina: Role of Demographic Characteristics and Acculturation - Barrick, Lattimore, Pitts and Zhang

\section{Individual-Level Indicators of Labor Trafficking}

Trafficking researchers have suggested that personal characteristics and acculturation or social isolation may increase an individual's vulnerability to human trafficking (Logan et al, 2009). Personal characteristics may include low levels of education, lack of understanding about legal rights, being female, and being young. Level of acculturation, including low (or no) English proficiency and being undocumented, increase social and cultural isolation and, in turn, increase an individual's vulnerability to exploitation. A recent review of the trafficking literature noted that young age and limited education have been found to place individuals at risk for trafficking (Clawson et al, 2009). Yet, there has been little research to substantiate these claims. The small body of research on characteristics of trafficking victims is, for the most part, limited to stakeholder interviews and reviews of known cases.

Clawson and associates conducted 121 telephone surveys with law enforcement personnel about their knowledge of and experience with human trafficking (Clawson et al., 2006). When asked about the most common warning signs that trafficking may be occurring, the lack of English speaking persons in an establishment was noted. In 2008, Newton and associates interviewed local human trafficking stakeholders in 60 counties, including law enforcement, prosecutors, and service provider agencies and organizations (Newton et al, 2008). Law enforcement respondents perceived that young age and undocumented legal status may indicate a trafficking situation.

Reviews of known trafficking cases also provide some insight into individual characteristics of trafficking victims. Clawson and colleagues conducted a review of all cases prosecuted under the TVPA between its enactment in October 2000 and December 2007 ( $\mathrm{n}=298)$ (Clawson et al, 2008). While victims represented many nationalities, they found that Mexicans comprised the largest percentage of trafficking victims. This case review was supplemented with interviews of federal prosecutors, who were asked to provide information about the cases they prosecuted under the TVPA. Prosecutors reported that the vast majority of their cases involved female victims; adults and minors were involved in about the same number of cases. In another case review, Farrell and colleagues fielded a nationally representative survey of law enforcement agencies to identify those which had investigated at least one human trafficking case between 2000 and 2006 (Farrell et al, 2008). They followed up with each agency responding affirmatively and asked them to provide information on the characteristics of the cases that had been investigated. Among labor trafficking cases, agencies reported that about half of the victims were between 18 and 24 years old and over $60 \%$ were male. More agencies reported that they encountered trafficking victims from Mexico than from any other country. When asked about indicators of trafficking, lack of English proficiency was noted by over half of the respondents.

Although case reviews and stakeholder interviews provide some useful information about labor trafficking, this information is limited to victims that are known to law enforcement. This is potentially problematic because labor trafficking is believed to be underidentified. This may be 
due, at least in part, to the inability of local law enforcement to recognize victims (Wilson, Walsh and Kleuber, 2006). For example, in a survey of police agencies Wilson and colleagues found that just over one-third of law enforcement respondents view trafficking as an issue for local law enforcement (Wilson et al, 2006). This is perhaps not surprising since only $8 \%$ of these agencies reported receiving training in human trafficking. Similarly, Farrell and colleagues reported that more than half of their law enforcement respondents believed that labor trafficking from outside or within the U.S. was non-existent (Farrell et al, 2008). If law enforcement does not believe trafficking exists or that it is an issue for law enforcement, then only a fraction of victims will ever be known. The limitations associated with relying solely on case reviews or interviews about known cases underscore the need to develop methods for identifying a population susceptible to labor trafficking.

In a groundbreaking study of labor trafficking, Zhang used respondent-driven sampling $(\mathrm{RDS})^{3}$, an incentivized and structured network-based referral process, to identify and interview over 800 undocumented workers in the San Diego area (Zhang, 2012). The interviews were used to estimate the prevalence of labor trafficking and other exploitation in San Diego and assess individual characteristics that may affect vulnerability to trafficking and other exploitation. This is the only study of which we are aware that examines individual correlates of labor trafficking among a sample of potential trafficking victims. In contrast to studies relying on case reviews or key informant interviews, Zhang found limited support for the notion that acculturation affects the likelihood of being victimized (Zhang, 2012). Of five measures of acculturation (education, English ability, number of times crossed into the U.S., number of times able to negotiate pay, and years in San Diego), only English ability was consistently associated with trafficking and other abuse. Somewhat surprisingly, respondents who were able to speak simple sentences in English were significantly more likely to be victimized than those who spoke a few words or no English and those who were proficient or fluent. Higher educational attainment was positively associated with risk for abuse but was not associated with trafficking. The length of time a respondent had been in San Diego was associated with increased risk for trafficking but not other forms of abuse. With regard to demographic characteristics, sex, marital status, and the number of children a respondent had were not associated with either trafficking or abuse.

\section{Current Study}

Thus, prior research suggests that demographic characteristics and level of acculturation may impact one's risk for labor trafficking victimization. However, these relationships have not been consistently demonstrated. Because labor trafficking hides within the confines of legitimate employment and because state and local law enforcement have had relatively little experience with labor trafficking cases, research that goes beyond the stakeholder interviews and case reviews that comprise much of the extant literature is needed. The current research sought to explore two primary research questions: (1) how prevalent is labor trafficking and other labor exploitation among farmworkers in North Carolina; and (2) do individual-level characteristics or 
Labor Trafficking Victimization among Farmworkers in North Carolina: Role of Demographic Characteristics and Acculturation - Barrick, Lattimore, Pitts and Zhang

circumstances place a person at greater risk of labor trafficking or other labor exploitation. More specifically, we assessed whether demographic characteristics and acculturation impact one's risk for labor trafficking. This was accomplished through information gathered from in-person interviews with migrant farmworkers in North Carolina.

\section{Data and Methods}

\section{Data Collection}

Location: Most forced labor cases involve migrant workers in economic sectors (such as agriculture) where the share of labor in the cost of production is highest and a main determinant of competitiveness (Belser, 2006). There are more than 2.1 million farms in the U.S., and the market value of agricultural products sold in 2012 reached nearly $\$ 400$ billion, over of which came from crops (Heckathorn, 1997). In the U.S., about 1.2 million laborers work on farms and ranches, 70 percent of whom are hired directly by the farm operators (United States Department of Agriculture, 2008). North Carolina is home to many of the business sectors that have been associated with poor working conditions, low wages, and human trafficking, including agriculture (such as "table crops" including cucumbers, potatoes, etc.), food processing (e.g., baked goods, pickles), poultry and pork production and processing, Christmas tree farming, landscaping, and construction. In 2012, North Carolina had over 50,000 farms yielding a market value of over $\$ 12$ billion in agricultural products, including $\$ 4.3$ billion from crops (Heckathorn, 1997). Additionally, North Carolina ranked $8^{\text {th }}$ in the country for total farm sales in 2012. According to the NC Farmworker Institute, about 150,000 migrant farmworkers and their dependents work in North Carolina, making the state sixth nationally in the number of migrant farmworkers (North Carolina Farmworker Institute, 2013). These characteristics make North Carolina an ideal location to study labor trafficking.

We first focused data collection on agriculture in predominantly rural counties in central and eastern North Carolina to develop in-depth information on exploitation and trafficking experiences within one industry in the state. In September and October of 2012 we conducted 257 interviews with farmworkers in nine counties in eastern and central North Carolina. We adjusted the target area to correspond to the primary crop in season during this period which was sweet potatoes. After the harvest season for table crops ended, we expanded the data collection to seven counties in western North Carolina, which has a large number of Christmas tree farms. We conducted 123 interviews with farmworkers in these western counties in November and December of 2012. Figure 1 shows the counties in which data was collected.

Farmworker Interview Instrument: The primary purpose of the farmworker interviews was to identify potential trafficking cases as well as indicators that trafficking may be occurring. An interview instrument with over 200 questions was developed to cover the following issues: demographics, housing, immigration experiences, agricultural experiences, trafficking/exploitation, movement within US, and the transport of goods into and within the US. 
To promote consistency in the definition and measurement of labor trafficking, we used trafficking/exploitation questions already developed and successfully used in San Diego by Zhang (2012). Questions about trafficking and exploitation covered five areas: victimization occurring while being transported into or within the U.S. (e.g., identification documents were withheld for control purposes), threats and fear (e.g., threats and perpetration of physical abuse, sexual abuse, or other harm), rules and control (e.g., prevention or restriction from communicating with others), deception and lies (e.g., type of work was different from expectations), and other exploitative labor practices (e.g., pay was denied or less than expected).

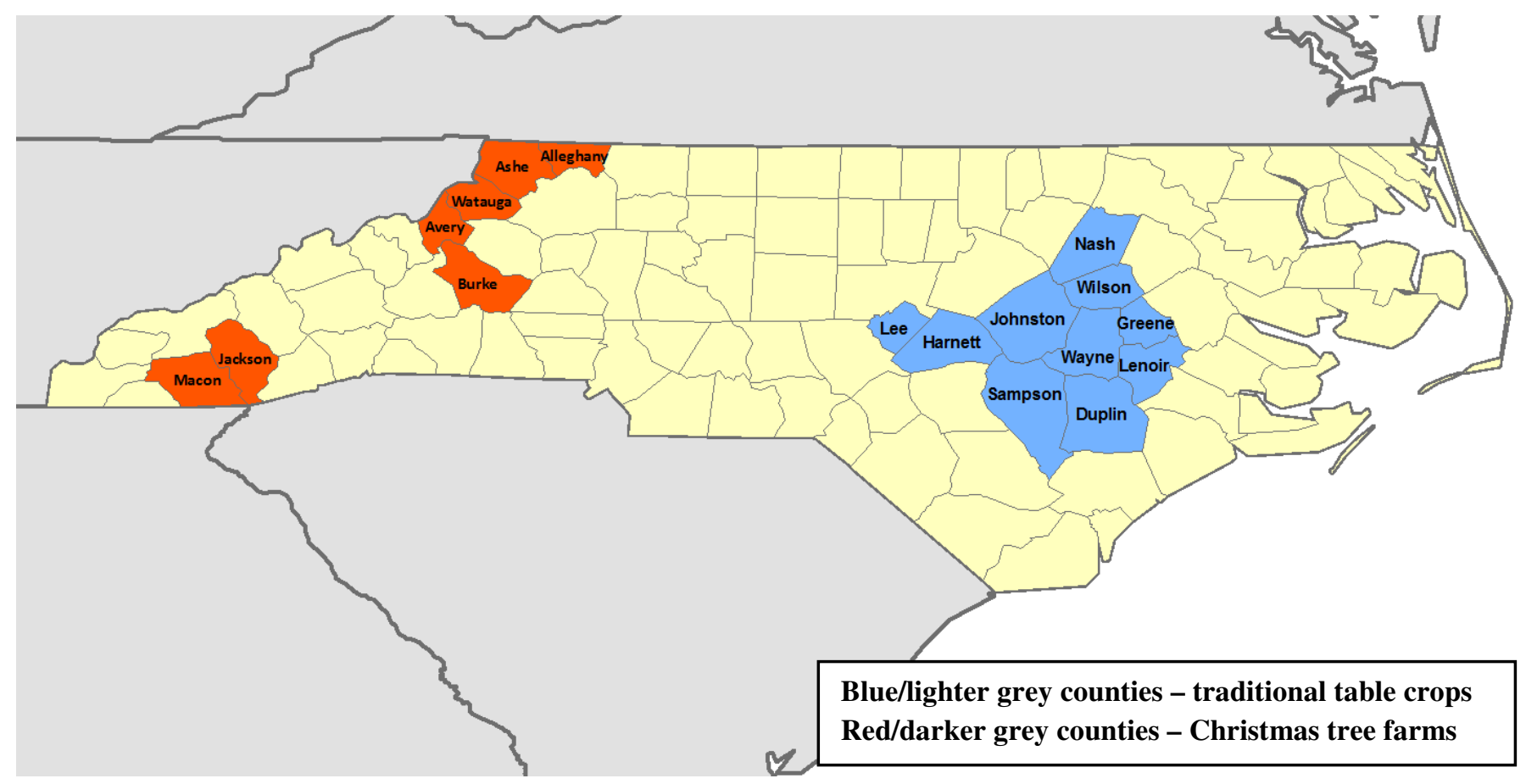

Figure 1: County Map of North Carolina

Fielding: Although Zhang (2012) demonstrated that RDS can be used to identify undocumented the isolation associated with farm work in rural areas, this approach is not feasible in the current study given the isolation associated with farmwork in rural areas. Instead, we used three strategies to identify migrant farmworkers: (1) community events; (2) labor camps; and (3) other public venues. A team of bilingual field interviewers was hired to conduct the data collection. First, the field interviewers went to two special community farmworker festivals to recruit respondents. At each event field interviewers arrived prior to the start of the event and engaged respondents by setting up a booth and walking among the crowds seeking willing respondents. These activities yielded 128 interviews.

Next, we extracted a database of registered farmworker labor camps from the North Carolina Department of Labor (2012) and supplemented it with notes collected by a local 
Labor Trafficking Victimization among Farmworkers in North Carolina: Role of Demographic Characteristics and Acculturation - Barrick, Lattimore, Pitts and Zhang

outreach organization, which has knowledge of camps that are not registered with the DOL, to identify farmworkers in central and eastern North Carolina counties with a high concentration of farming activities. This strategy allowed us to overcome some of the limitations inherent in interviewing farmworkers who are able to attend festivals; those who are unable or not allowed to attend these community events are probably more vulnerable to trafficking. We conducted 129 interviews at labor camps in eastern and central North Carolina.

Later in the season, a team of interviewers made multiple trips to western North Carolina to interview workers in the Christmas tree industry. While many Christmas tree farms were identified, farmworker housing was far more integrated into the community and more difficult to identify. The team screened the area looking for possible housing areas. Some of the possible indicators of migrant worker housing included passenger vans, twin cab pick-up trucks with equipment or trailers for hauling trees, out-of-state license plates, mobile home parks, lower-end motels, and many pairs of boots outside on a porch. The team also asked local residents about places where concentrations of farmworkers were living. Using these techniques, the team screened the area looking for possible housing areas and identified many. Another strategy emerged during these excursions that was especially effective. The teams visited businesses where farmworkers go when they are not working - laundromats, Latino stores, and bus stations. We conducted 123 interviews in housing areas and businesses in western North Carolina.

Completion of the surveys, including time to introduce the survey and obtain consent, took approximately 15-20 minutes. Compensation for time (items worth about \$15) was provided to the respondents recruited through each of the three approaches. For most of the study, we provided bilingual, picture dictionaries as compensation, which proved popular with respondents. Towards the end of the data collection period, the team experimented with a variety of other incentives including: makeup kits, mini-soccer balls, perfume/cologne, flashlights, a variety of tools (pliers, screw drivers, wrenches), pocket knives, hats, stationary kits (pens and paper), blankets, school supplies, cooking pots, and stuffed animals. The most often chosen incentives were flashlights, hats, and tools.

\section{Measures}

Dependent Variables: Our primary outcomes of interest were trafficking and other abusive labor practices. Following Zhang, trafficking was measured conservatively, only including actual or threatened infringement of freedom of movement and actual or threatened physical violence (Zhang, 2012, p. 50). Abusive practices included other grossly unfair treatment or exploitative practices, such as fraud and deception. A list of all items that were used to identify potential victims and differentiate between trafficking and non-trafficking abuse by type of perpetrator (i.e., someone assisting with transportation and employers) are presented in the Appendix. Workers who responded affirmatively to at least one item in the first column (trafficking violations) were coded as having experienced trafficking; those who responded affirmatively to at least one of the items in the second column (non-trafficking violations) were coded as having 
experienced non-trafficking abuse. Individuals who reported experiencing either a trafficking violation or non-trafficking abuse were coded as having experienced any violation.

Independent Variables: Based on prior research, we identified a number of individual characteristics that may impact one's vulnerability to trafficking. We included the following demographic characteristics: age; sex $($ male=1); marital status (single, married, cohabitating, and other); and number of children. We measured acculturation through the following five items: highest level of education (none, primary, secondary, and more than secondary); English ability (none, a few words, simple sentences, and proficient or fluent); number of times crossed into the U.S.; years in North Carolina; legal status (undocumented=1); and nationality (Mexican=1).

\section{Results}

Characteristics of the 380 farmworkers who participated in the research are presented in Table 1. On average, respondents were 35 years old and the vast majority was male. Most of the respondents were either married $(46 \%)$ or cohabitating $(21 \%)$; less than one in three were single. The workers reported having an average of two children. Educational attainment was extremely low. Nearly half of the workers had either no education or only completed primary school; $37 \%$ completed secondary school and only $16 \%$ had more than a secondary education. The workers also knew very little English. Nearly one-third knew no English and nearly half knew only a few words; $11 \%$ could make simple sentences and $9 \%$ were proficient or fluent in English. The average worker had crossed into U.S. nearly five times and had been in North Carolina for over 2 years. The overwhelming majority of respondents were from Mexico (94\%) and nearly $42 \%$ were undocumented. The vast majority of workers who reported having legal status in the U.S. had an H-2A visa, which provides temporary legal status for agricultural workers meeting certain requirements.

A summary of the reported prevalence of trafficking and other labor abuses is presented in Table 2. About one-quarter of respondents reported ever experiencing a situation that may constitute trafficking and 39\% reported other abuse. Among workers who reported traveling with a "coyote", an individual who assists workers with transportation to or within the U.S., results were similar. One in five workers reported experiencing trafficking at the hands of their employer and one in three reported experiencing other abuse. The most common type of exploitation was abusive labor practices (34\%), followed by deception and lies (21\%), restriction and deprivation (15\%), and threats to physical integrity (12\%).

To examine whether demographic characteristics and level of acculturation are associated with risk for trafficking and other forms of abuse, we ran a series of logistic regression models. Given the relatively small sample, we first examined demographic and acculturation measures separately. Then, we entered each of the significant characteristics into a full model to determine which characteristics remain significant when other variables are held constant. The results are presented in Table 3. Model 1 includes only the demographic characteristics. Male farmworkers 
Labor Trafficking Victimization among Farmworkers in North Carolina: Role of Demographic Characteristics and Acculturation - Barrick, Lattimore, Pitts and Zhang

Table 1: Characteristics of Farmworkers $(n=380)$

\begin{tabular}{|l|c|c|}
\hline & $\begin{array}{c}\text { Mean or } \\
\%\end{array}$ & $\begin{array}{c}\text { Std. } \\
\text { Dev. }\end{array}$ \\
\hline Age & 35.26 & 10.47 \\
\hline Male & 89.21 & 0.31 \\
\hline Marital status & & \\
\hline Single & 28.95 & 0.45 \\
\hline Married & 45.53 & 0.50 \\
\hline Living together & 21.05 & 0.41 \\
\hline Widowed, divorced, or living together & 4.47 & 0.21 \\
\hline Number of children & 2.21 & 1.91 \\
\hline Highest level of education attained & & \\
\hline None & 15.30 & 0.36 \\
\hline Primary & 31.40 & 0.46 \\
\hline Secondary & 37.20 & 0.48 \\
\hline More than secondary & 16.09 & 0.37 \\
\hline English proficiency & & \\
\hline No English & 31.84 & 0.47 \\
\hline Only a few words & 47.63 & 0.50 \\
\hline Simple sentences & 11.32 & 0.32 \\
\hline Proficient or fluent & 9.21 & 0.29 \\
\hline Number of times crossed into the U.S. & 4.76 & 5.28 \\
\hline Years in North Carolina & 2.07 & 4.23 \\
\hline Undocumented & 41.93 & 0.49 \\
\hline Nationality & & \\
\hline Mexico & 94.46 & 0.23 \\
\hline Other country & 5.54 & 0.23 \\
\hline
\end{tabular}

Table 2: Summary of Trafficking and Abusive Practices

\begin{tabular}{|l|c|c|c|}
\hline & $\mathrm{N}$ & $\%$ & Std. Dev. \\
\hline Any violation & 373 & 45.00 & 0.50 \\
\hline Trafficking violation & 373 & 25.47 & 0.44 \\
\hline Abusive practice & 372 & 39.25 & 0.49 \\
\hline Any violation during transportation* & & & \\
\hline Trafficking violation & 142 & 19.72 & 0.40 \\
\hline Abusive practice & 143 & 38.46 & 0.49 \\
\hline Employer violation & & & \\
\hline Trafficking violation & 373 & 20.38 & 0.40 \\
\hline Abusive practice & 372 & 33.60 & 0.47 \\
\hline Employer violation type & & & \\
\hline Threat to physical integrity & 373 & 12.33 & 0.33 \\
\hline Restriction/deprivation & 373 & 15.01 & 0.36 \\
\hline Deception/lies & 372 & 20.97 & 0.41 \\
\hline Abusive practices & 372 & 33.60 & 0.47 \\
\hline
\end{tabular}

*Among respondents who traveled with a coyote 
were significantly less likely than females to report experiencing either trafficking or other abuse. Additionally, married farmworkers were less likely to report abuse (but not trafficking) than their single counterparts. Neither age nor number of children was associated with trafficking or other abuse.

Model 2 presents the findings for the five measures of acculturation. Length of time in North Carolina was negatively associated with abuse (but not trafficking). We also found that respondents who knew some English were more likely to experience trafficking and other abuse than those who spoke no English. Workers who reported being undocumented when they last entered the U.S. were significantly more likely to report trafficking and other abuse than those who entered with a H-2A visa or other legal status and the effects are large; the odds of a worker who was undocumented being trafficked and abused were four and eight times higher (respectively) than those with legal status.

Next, we examined demographic characteristics and acculturation together by including all variables that were significant in the first two models into Model 3. The results changed very little when demographics and acculturation were examined jointly. Male farmworkers were still significantly less likely to experience trafficking but the coefficient for other abuse is no longer significant. Although being married was no longer protective for abuse, time in North Carolina remained significant. English proficiency and documentation status remained the strongest and most consistent predictors of trafficking and other abuse. Workers with greater English proficiency were more likely to report experiencing trafficking and other exploitation. A worker's legal status was the strongest and most consistent predictor of experiencing trafficking and other violations. The odds that an undocumented worker will experience trafficking or other abuse were 3.2 and 7.1 times greater, respectively, than those of a worker with legal status.

\section{Discussion}

Scholars have suggested that labor trafficking is an underidentified crime and most research on labor trafficking has focused on known cases through conducting stakeholder interviews and reviewing police and court case files. The current study builds on the existing literature by interviewing farmworkers in North Carolina who may be at risk for labor trafficking and other exploitation. We examined the prevalence of trafficking abuse and assessed whether demographic characteristics and acculturation play a role in risk for victimization. Experiences of abuse were not uncommon among the farmworkers interviewed. Nearly half (45\%) reported experiencing some victimization; $25 \%$ reported potential trafficking; and 39\% reported other abuse and exploitation. While abusive practices (34\%) and deception and lies $(21 \%)$ were the most common types of offenses reported, $15 \%$ of workers reported being restricted or deprived and $12 \%$ reported threats to physical security.

For the most part, demographic characteristics were not strongly associated with trafficking or other abuse. In the full model, male farmworkers were significantly less likely than females to 
Labor Trafficking Victimization among Farmworkers in North Carolina: Role of Demographic Characteristics and Acculturation - Barrick, Lattimore, Pitts and Zhang

Table 3: Logistic Regression Models of Individual Level Indicators of Labor Trafficking and Abusive Practices

\begin{tabular}{|c|c|c|c|c|c|c|c|c|c|c|c|c|c|c|c|c|c|c|}
\hline & \multicolumn{6}{|c|}{ Model 1: Demographic Characteristics } & \multirow{2}{*}{\multicolumn{6}{|c|}{ Model 2: Acculturation }} & \multicolumn{6}{|c|}{ Model 3: Full Model } \\
\hline & \multicolumn{3}{|c|}{ Trafficking } & \multicolumn{3}{|c|}{ Abuse } & & & & & & & \multicolumn{3}{|c|}{ Trafficking } & \multicolumn{3}{|c|}{ Abuse } \\
\hline & Coef & OR & $\mathrm{p}$ & Coef & OR & $\mathrm{p}$ & Coef & $\mathrm{OR}$ & $\mathrm{p}$ & Coef & OR & $\mathrm{p}$ & Coef & OR & $\mathrm{p}$ & Coef & $\mathrm{OR}$ & $\mathrm{p}$ \\
\hline Variables & & & & & & & & & & & & & & & & & & \\
\hline Age & 0.02 & 1.02 & .21 & -0.01 & 0.99 & .67 & & & & & & & & & & & & \\
\hline Male & -0.72 & 0.49 & .05 & -0.82 & 0.44 & .02 & & & & & & & -0.79 & 0.45 & .05 & -0.52 & 0.59 & .20 \\
\hline Marital status & & & & & & & & & & & & & & & & & & \\
\hline Single & & & & & & & & & & & & & & & & & & \\
\hline Married & -0.39 & 0.68 & .24 & -0.67 & 0.51 & .03 & & & & & & & 0.27 & 1.31 & .41 & -0.21 & 0.81 & .50 \\
\hline $\begin{array}{l}\text { Living } \\
\text { together }\end{array}$ & -0.52 & 0.59 & .17 & -0.41 & 0.66 & .20 & & & & & & & -0.28 & 0.75 & .48 & -0.20 & 0.82 & .57 \\
\hline Other & 0.23 & 1.26 & .69 & -0.19 & 0.83 & .74 & & & & & & & 0.85 & 2.33 & .15 & -0.58 & 0.56 & .34 \\
\hline $\begin{array}{l}\text { Number of } \\
\text { children }\end{array}$ & 0.07 & 1.08 & .35 & -0.02 & 0.98 & .83 & & & & & & & & & & & & \\
\hline $\begin{array}{l}\text { Educational } \\
\text { attainment }\end{array}$ & & & & & & & & & & & & & & & & & & \\
\hline None & & & & & & & & & & & & & & & & & & \\
\hline Primary & & & & & & & -0.31 & 0.73 & .46 & -0.35 & 0.70 & .39 & & & & & & \\
\hline Secondary & & & & & & & -0.46 & 0.63 & .28 & -0.19 & 0.82 & .64 & & & & & & \\
\hline $\begin{array}{l}\text { More than } \\
\text { secondary }\end{array}$ & & & & & & & -0.35 & 0.70 & .51 & -0.77 & 0.46 & .14 & & & & & & \\
\hline $\begin{array}{l}\text { English } \\
\text { ability }\end{array}$ & & & & & & & & & & & & & & & & & & \\
\hline None & & & & & & & & & & & & & & & & & & \\
\hline $\begin{array}{l}\text { A few } \\
\text { words }\end{array}$ & & & & & & & 0.78 & 2.18 & .03 & 0.59 & 1.80 & .06 & 0.92 & 2.52 & .01 & 0.64 & 1.90 & .03 \\
\hline $\begin{array}{l}\text { Simple } \\
\text { sentences }\end{array}$ & & & & & & & 0.92 & 2.50 & .08 & 0.70 & 2.02 & .15 & 0.80 & 2.23 & .09 & 0.82 & 2.27 & .06 \\
\hline $\begin{array}{l}\text { Proficient } \\
\text { /fluent }\end{array}$ & & & & & & & 0.82 & 2.27 & .14 & 0.89 & 2.43 & .10 & 1.28 & 3.61 & .01 & 0.69 & 1.99 & .15 \\
\hline $\begin{array}{l}\text { Number of } \\
\text { times crossed } \\
\text { into the U.S. }\end{array}$ & & & & & & & 0.04 & 1.04 & .21 & 0.00 & 1.00 & .89 & & & & & & \\
\hline Years in NC & & & & & & & 0.02 & 1.02 & .56 & -0.08 & 0.92 & .04 & 0.00 & 1.00 & .90 & -0.06 & 0.95 & .10 \\
\hline $\begin{array}{l}\text { Undocum- } \\
\text { ented }\end{array}$ & & & & & & & 1.41 & 4.08 & .00 & 2.09 & 8.11 & .00 & 1.15 & 3.16 & .00 & 1.97 & 7.14 & .00 \\
\hline Mexican & & & & & & & 0.50 & 1.65 & .44 & -0.25 & 0.78 & .68 & & & & & & \\
\hline $\begin{array}{l}\text { Nagelkerke } \\
\text { R Square }\end{array}$ & \multicolumn{3}{|c|}{0.046} & \multicolumn{3}{|c|}{0.053} & \multicolumn{3}{|c|}{0.135} & \multicolumn{3}{|c|}{0.269} & \multicolumn{3}{|c|}{0.152} & \multicolumn{3}{|c|}{0.256} \\
\hline
\end{tabular}

experience trafficking. This is consistent with prior findings that the majority of known trafficking cases involve women (Clawson et al, 2008; Logan et al, 2009). However, Zhang (2012) found no impact of gender on risk for violations and Farrell and associates reported that more prosecuted cases of labor trafficking involved male than female victims (Farrell et al, 2008). None of the other demographic characteristics (i.e., age, marital status, or number of children) were found to be related to victimization, which is consistent with Zhang's findings in San Diego (Zhang, 2012).

More support was found for the impact of acculturation on trafficking and other abuse than demographic characteristics. Higher levels of English proficiency put workers at greater risk for trafficking and other exploitation. This was not consistent with acculturation expectations that those who were less culturally isolated (i.e., could communicate better in English) would be less vulnerable to abuse. Yet, it is consistent with Zhang's finding that those who could speak simple 
sentences in English were more likely to experience trafficking and other violations than those who only spoke a few words (Zhang, 2012). In discussions with advocates, as well as anecdotal findings during stakeholder interviews conducted during an earlier phase of this study, possible explanations for this finding emerged. These include (1) English speakers may be more likely to understand that they are being abused or mistreated; (2) English speakers may have more interaction with owners, crew leaders, and others in authority and, thus, may be more frequent targets of abuse; and (3) English speakers may be more forthcoming during the interviews (although interviews were conducted in Spanish). The first and third explanations would suggest that the observed difference is due to differences in recognition and reporting and not of actual differences in abuse. The second posits an explanation for why there may be an actual differences in abuse. Future research should collect information to address these (and other) explanations, as well as to confirm the findings.

A worker's legal status was the strongest and most consistent predictor of experiencing trafficking and other violations. Relative to the odds of those with an H-2A visa or other legal documentation, the odds of undocumented workers were three times higher for trafficking and seven times higher for other abuse. This finding is consistent with the expectations of other scholars (Logan et al, 2009; Newton et al, 2008) who suggest that being undocumented increases one's vulnerability to exploitation. Because the vast majority of documented workers were participating in the $\mathrm{H}-2 \mathrm{~A}$ visa program, this finding may also suggest that the regulation and oversight of farmworker labor for this program provides some protection for farmworkers. The H-2A visa program, a guestworker program administered by the U.S. Citizenship and Immigration Services (USCIS), provides some legal protections for temporary foreign farmworkers through federal law and Department of Labor regulations (Southern Poverty Law Center, 2013). However, it is important to note that this guestworker program has been the subject of much criticism, including that employers hold the "deportation card" (Southern Poverty Law Center, 2013, p. 15), the program is structured such that the decision about whether a worker can come to the U.S. and stay in the U.S. is made by the employer, not the worker (Southern Poverty Law Center, 2013). Moreover, workers are only permitted to work for one employer and cannot seek other employment for any reason. It is also important to recognize that while the legal protections are the same, the oversight of the H-2A program varies by state and the findings reported here are not generalizable to other states. Indeed, local farmworker advocates relayed to us that $\mathrm{NC}$ has one of the best $\mathrm{H}-2 \mathrm{~A}$ programs in the country and even includes a farmworker union. Additional research is needed to assess the impact of $\mathrm{H}-2 \mathrm{~A}$ participation on the lives of farmworkers.

Like all research, the current study is not without limitations. First, the research presented here is admittedly exploratory. However, it represents a significant improvement over existing labor trafficking literature, which primarily relies on law enforcement and stakeholder 
interviews, by collecting data from a sample of farmworkers who are potentially in trafficking situations. Additionally, the research was only conducted in one industry in one state and relied on a convenience sample of farmworkers, which limits the generalizability of the findings.

This study found that labor trafficking activities and abusive labor practices among migrant farmworkers were common in parts of North Carolina. Although our study was not based on probability sampling, the high frequencies of identified trafficking activities and other abusive labor law violations warrant additional validation using more rigorous sampling methods. Considering the large number of migrant farmworkers in North Carolina, any sizeable percentage of verified labor trafficking activities could suggest a large population of trafficking victims. Human trafficking research involving systematic data collection and quantitative measures remains rare in the U.S. and other countries. However, valid empirical estimates on the scope of the problems are imperative for resource allocation as well as for effective policy development.

Future research should aim to use probability sampling to estimate the prevalence of labor trafficking both in agriculture and in other industries in which workers are vulnerable to exploitation and abuse, such as meatpacking and food processing, domestic work, factories and manufacturing, restaurants, peddling and begging rings, and hospitality, among others. This is difficult given the hidden nature of the population and requires the use of innovative research designs. There are a couple promising approaches to measuring prevalence, including RDS and GeoFrame $^{\mathrm{TM}}$.

As described earlier, RDS is an improvement over traditional snowball sampling that uses an incentivized and structured chain referral system. Zhang demonstrated the successful application of RDS to the study of labor trafficking among undocumented workers in San Diego. This technique should be applied in other geographic areas and with other populations. Although this is a strong strategy for obtaining prevalence estimates in a relatively small area (i.e., city or county), it may not be well-suited to larger geographic units (i.e., states or nations) because it relies on social networks.

Another promising approach is to incorporate geo-mapping techniques to create a sampling frame of potential trafficking victims. The authors of this paper piloted, and are in the process of fully implementing, GeoFrame ${ }^{\mathrm{TM}}$, a technique developed to enumerate hidden populations that employs the capture of digital images with GPS coordinates (Even, Quiroz, Athey, McMichael and Albright, 2008; McMichael, Athey and Albright, 2008; Evans, B.M., Quiroz, R.S., Athey, L.A., McMichael, J.P., and Albright, V. A. 2008). The digital image and GPS coordinates serve as a surrogate to what would be a households address or description with traditional field enumeration. For use with farmworker populations, geographic data on farming practices can be 
extracted at the census block level to identify areas where migrant farmworkers may live (Pitts, Barrick, Lattimore and Zhang, under review). This technique is most useful when geographic characteristics can be used to narrow down where the population of interest will be. It may not be particularly useful for identifying victims in certain industries that are less clustered than agriculture, such as domestic work, construction, and landscaping.

\section{Endnotes}

${ }^{1}$ This project was sponsored by Grant Number 2009-IJ-CX-0047, awarded by the National Institute of Justice, Office of Justice Programs, U.S. Department of Justice. Points of view are those of the authors and do not necessarily represent the official position or policies of the U.S. Department of Justice.

${ }^{2} \mathrm{RTI}$ International is an independent organization dedicated to conducting innovative, multidisciplinary research that improves the human condition.

${ }^{3}$ Heckathorn (1997) introduced RDS, which was designed to overcome problems inherent in traditional snowball sampling techniques [27]. As described by Zhang (p. 6), "RDS relies on the Markov property of its structured referral process to achieve both diversity and equilibrium (the point at which initial samples no longer mirror later samples) through successive waves of participant recruitment. By using an incentivized and structured chain referral system, the RDS method allows unbiased estimation of the target population." 
Labor Trafficking Victimization among Farmworkers in North Carolina: Role of Demographic Characteristics and Acculturation - Barrick, Lattimore, Pitts and Zhang

\section{References}

Bales, K., \& Lize, S. (2005). Trafficking in persons in the U.S. Final report submitted to the National Institute of Justice, Office of Justice Programs, U.S. Department of Justice. Available at http://www.ncjrs.gov/pdffiles1/nij/grants/211980.pdf

Belser, P. (2005). Forced labour and human trafficking: Estimating the profits. Geneva: International Labour Office. Available at: http://ilo.org.

Belser, P., de Cock, M., \& Mehran, F. (2005). An ILO minimum estimate of forced labor in the world. Geneva, Switzerland: International Labor Organization. Retrieved from http://www.ilo.org/.

Chin, K. (1999). Smuggled Chinese: Clandestine Immigration to the United States. Philadelphia: Temple University Press.

Clawson, H.J., Dutch, N., \& Cummings M. (2006). Law enforcement responses to human trafficking and the implications for victims: Current practices and lessons learned. Fairfax, VA :Caliber. Available at: http://ojp.usdoj.gov/nij/international/programs/inttraffick.html

Clawson, H.J., Dutch, N., Lopez, S., \& Tiapula, S. (2008). Prosecuting human trafficking cases: Lessons learned and promising practices. Final Report submitted to the National Institute of Justice, Office of Justice Programs, U.S. Department of Justice. Available at: http://www.ncjrs.gov/app/Search/Abstracts.aspx?id=245913.

Clawson, H.J., Dutch, N., Solomon, A., \& Grace, L.G. (2009). Human trafficking into and within the United States: A review of the literature. Report submitted to the U.S. Department of Health and Human Services, Office of the Assistance Secretary for Planning and Evaluation. Available at: http://aspe.hhs.gov/hsp/07/humantrafficking/litrev/

Evans, B.M., Quiroz, R.S., Athey, L.A., McMichael, J.P., \& Albright, V. A. 2008. Customizing survey methods to the target population - innovative approaches to improving response rates and data quality among Hispanics. Presented at American Association of Public Opinion Researchers (May, 2008), New Orleans, LA.

Farrell, A., McDevitt, J., \& Fahy, S. (2008). Understanding and improving law enforcement responses to human trafficking. Final Report submitted to the National Institute of Justice, Office of Justice Programs, U.S. Department of Justice. Available at: http://www.ncjrs.gov/pdffiles1/nij/grants/222752.pdf

Garrett, R. (2008). Imprisoned in the American nightmare. Law Enforcement Technology, September 2008. Available at: http://www.officer.com/article/10248645/imprisoned-in-theamerican-nightmare. 
Government Accountability Office. (2006, July). Human trafficking: Better data, strategy, and reporting needed to enhance U.S. anti-trafficking efforts abroad. Washington, DC: United States Government Accountability Office.

Goździak, E.A., \& Bump, M.N. (2008). Data and research on human trafficking: Bibliography of research-based literature. Final Report submitted to the National Institute of Justice, Office of Justice Programs, U.S. Department of Justice. Available at: http://isim.georgetown.edu/Publications/ElzPubs/NIJ_BIB_FINAL_REPORT-1.pdf

Heckathorn, D.D. (1997). Respondent-driven sampling: A new approach to the study of hidden populations. Social Problems, 44, 174-199.

Human Smuggling and Trafficking Center (2006). Fact sheet: Distinctions between human smuggling and human trafficking. Available at: http://www.state.gov/m/ds/hstcenter/90434.htm

Laczko, F. (2002). Human trafficking: The need for better data. Geneva: International Organization for Migration. Available at:: http://www.migrationinformation.org/Feature/display.cfm?ID=66

Laczko, F. \& Goździak, E. (2005). Data and research on human trafficking: A global survey. Geneva: International Organization for Migration. Available at: http://www.nswp.org/pdf/IOM-GLOBALTRAFFICK.PDF

Laczko, F. \& Gramegna, M.A. (2003). Developing better indicators of human trafficking. Brown Journal of World Affairs, 10 (1), 179-194.

Logan, T.K., Walker, R., \& Hunt, G. (2009) Understanding human trafficking in the United States. Trauma, Violence, and Abuse, 10, 3-30.

McMichael, J.P., Athey, L.A., Evans, B.M., \& Albright, V. A. 2008. GeoFrame: A technological advancement in field enumeration. Presented at Joint Statistical Meetings (August, 2008), Denver, CO.

Minnesota Statistical Analysis Center. (2006). Human trafficking in Minnesota: A report to the Minnesota Legislature. Saint Paul, Minnesota: Author.

Newton, P.J., Mulcahy, T.M., \& Martin, S.E. (2008). Finding victims of human trafficking. Final Report submitted to the National Institute of Justice, Office of Justice Programs, U.S. Department of Justice. 
Labor Trafficking Victimization among Farmworkers in North Carolina: Role of Demographic Characteristics and Acculturation - Barrick, Lattimore, Pitts and Zhang

North Carolina Department of Labor, Agricultural Safety and Health Bureau. (2012). Migrant Housing Sites Map. Available at: https://www.dol.communications.its.state.nc.us/ash/scripts/pa_1a.cfm

North Carolina Farmworker Institute (2013). Introduction to farm work. Available at: http://www.ncfarmworkers.org/learn/introduction-to-farm-work/

Pitts, W.J., Barrick, K., Lattimore, P.K., Zhang, S.X. (under review). Estimating labor trafficking among farmworkers: An inverse sampling strategy based on reliable housing predictions.

Southern Poverty Law Center (2013). Close to slavery: Guestworker programs in the United States. Montgomery, AL: Southern Poverty Law Center. Available at:

http://www.splcenter.org/get-informed/publications/close-to-slavery-guestworker-programsin-the-united-states

United Nations Office on Drugs and Crime (2009). Global report on trafficking in persons. New York: United Nations Office on Drug and Crime (UNODC). Available at: http://viewer.zmags.com/showmag.php?magid=142247\#/page0/

United States Department of Agriculture, National Agricultural Statistical Services (NASS). (2008). Farm labor. Retrieved from http://www.nass.usda.gov/.

United States Department of Agriculture. (2012). 2012 Census of agriculture: Preliminary report. U.S. and state data. Available at: http://www.agcensus.usda.gov/Publications/2012/Preliminary_Report/Full_Report.pdf

U.S. Department of Justice (2006). Assessment of U.S.government activities to combat trafficking in persons in Fiscal Year 2005. Washington, DC: Available at: http://www.justice.gov/archive/ag/annualreports/tr2006/assessment_of_efforts_to_combat_ tip.pdf

Wilson, D.G., Walsh, W.F., \& Kleuber, S. (2006). Trafficking in human beings: Training and services among US law enforcement agencies. Police Practice and Research, 7, 149-160.

Zhang, S.X. (2012). Looking for a hidden population: Trafficking of migrant laborers in San Diego County. Final Report submitted to the National Institute of Justice, Office of Justice Programs, U.S. Department of Justice. 


\section{Appendix: Survey Items Used to Measure Trafficking and Abusive Practices}

\begin{tabular}{|c|c|}
\hline Trafficking Violations & Non-Trafficking Violations \\
\hline \multicolumn{2}{|c|}{$\begin{array}{c}\text { Transportation (experienced during the most recent trip to the U.S. } \\
\text { or during travel since the most recent arrival) }\end{array}$} \\
\hline $\begin{array}{l}\text { Your identification documents were withheld not } \\
\text { for safekeeping or travel convenience but for } \\
\text { control purposes } \\
\text { You were held hostage at or prevented from } \\
\text { leaving a safe hour before or after you crossed } \\
\text { into the U.S. while the coyotes were demanding } \\
\text { ransom from your family }\end{array}$ & $\begin{array}{l}\text { - You were forbidden from leaving the traveling } \\
\text { group, or restricted where you could go } \\
\text { - You were forbidden or restricted from } \\
\text { communicating freely with your family } \\
\text { - You were forbidden or restricted from } \\
\text { communicating freely with other travelers } \\
\text { - You were assaulted or fined when you failed to } \\
\text { obey the coyote's rules } \\
\text { - You were threatened to be assaulted or fined } \\
\text { when you failed to obey the coyote's rules } \\
\text { You/your family were required to pay more } \\
\text { smuggling fees than originally agreed or bad } \\
\text { things would happen to you or your family }\end{array}$ \\
\hline \multicolumn{2}{|c|}{ Employer } \\
\hline $\begin{array}{l}\text { Threats and fear (ever experienced): } \\
\text { - Physical abuse (including beating, kicking, } \\
\text { - } \quad \text { Slapping, etc.) } \\
\text { - Threal abuse } \\
\text { kicking, slapping, etc.) } \\
\text { - Threats of sexual abuse } \\
\text { - Locked up (including physically restrained) } \\
\text { - Threats of harm to you in any other form } \\
\text { - Threats of harm to your family in any form } \\
\text { - Threats to get you deported } \\
\text { - Threats to get you arrested } \\
\text { - Threats to turn you over to police or immigration } \\
\quad \text { officials }\end{array}$ & $\begin{array}{l}\text { Deception and lies (experienced at most recent job): } \\
\text { - } \quad \text { Pay was less than you were promised } \\
\text { - The type of work was different from what you } \\
\text { - } \text { were promised } \\
\text { - } \text { you werk environment was different from what } \\
\text { - The amount of work was different from what you } \\
\text { - } \quad \text { You were told that you will not be believed if } \\
\text { - you try to seek help from U.S. authorities } \\
\text { - You were instructed to lie about your identity } \\
\quad \text { you were instructed to lie about the identity of } \\
\text { your employer }\end{array}$ \\
\hline $\begin{array}{l}\text { Rules and control (ever experienced): } \\
\text { - You were forbidden from leaving the workplace } \\
\text { - You were restricted where you could go during } \\
\text { non-working hours } \\
\text { - Your identification papers were taken away, not } \\
\text { for safekeeping but for control purposes } \\
\text { - You were not allowed adequate food or sleep } \\
\text { - You were prevented or restricted from } \\
\text { - } \quad \text { Youmunicating freely with your family } \\
\text { communicating freely with other workers } \\
\text { - You were prevented or restricted from } \\
\text { communicating freely with others outside the } \\
\text { workplace }\end{array}$ & $\begin{array}{l}\text { Exploitative labor practices (ever experienced): } \\
\text { - You were denied pay for work you performed in } \\
\text { the U.S. } \\
\text { - You received less pay than what you were } \\
\text { - } \quad \text { Youmised } \\
\text { - Your emploived a bad check from your employer } \\
\text { - You were told to work in hazardous } \\
\text { - } \quad \text { Youvironments without proper protection } \\
\text { consider abusive or exploitative }\end{array}$ \\
\hline
\end{tabular}

